\title{
Introducción
}

\section{Thérèse Bouysse-Cassagne}

\section{(2) OpenEdition}

Journals

Edición electrónica

URL: http://journals.openedition.org/bifea/4831

DOI: 10.4000/bifea.4831

ISSN: 2076-5827

\section{Editor}

Institut Français d'Études Andines

\section{Edición impresa}

Fecha de publicación: 1 diciembre 2005

Paginación: 273-276

ISSN: 0303-7495

\section{Referencia electrónica}

Thérèse Bouysse-Cassagne, «Introducción », Bulletin de l'Institut français d'études andines [En línea], 34 (3) | 2005, Publicado el 08 diciembre 2005, consultado el 02 diciembre 2020. URL : http:// journals.openedition.org/bifea/4831 ; DOI : https://doi.org/10.4000/bifea.4831

\section{(c) (i) (9)}

Les contenus du Bulletin de l'Institut français d'études andines sont mis à disposition selon les termes de la licence Creative Commons Attribution - Pas d'Utilisation Commerciale - Pas de Modification 4.0 International. 


\section{Introducción}

\section{Thérèse Bouysse-Cassagne*}

Dos reuniones en torno a las Dinámicas culturales y las identidades en el Centro-Sur andino tuvieron lugar, por la primera, en la sede del IFEA en Lima (26-27 de noviembre de 2001), organizada por el IFEA y la Embajada de Finlandia en Perú y, por la segunda, en la Paz, donde se convocó a investigadores oriundos de Argentina, Bolivia, Chile, Perú y Europa, arqueólogos, antropólogos, historiadores y gestores culturales, sobre el mismo tema.

Esta última convocatoria fue organizada por el IFEA, el IRD-Bolivia, la Embajada de Francia en Bolivia y la Cooperación francesa para el Cono sur.

Estos dos coloquios fueron precedidos por un concurrido Congreso internacional de expertos para toda America Latina, en el que participaron algunos de los autores de este número especial del Bulletin de I'IFEA. Aquel congreso, patrocinado por el Centro Ibero-Americano de la Universidad de Helsinki y la Comisión Europea (Túsula, 2-4 noviembre de 1999) se interesó por los temas prioritarios propuestos en Rio en 1999, a saber la recuperación, la conservación y los estudios sobre el patrimonio.

$\mathrm{Al}$ convocar las dos últimas reuniones, nuestro objetivo era ubicar la Historia al interfaz de las distintas tradiciones culturales de varios países del Centro-Sur andino, fijándonos como tarea, independientemente del periodo considerado, precisar las influencias, señalar las resistencias, tomar en cuenta las mutilaciones históricas, así como todo lo que resiste al analisis (Ginzburg, 1980). Se trataba de privilegiar los procesos en relación con las estructuras o las instituciones a fin de resolver una de las ambigüedades fundamentales de los trabajos sobre temas identitarios y el patrimonio: cierta tendencia en pensar en términos de agregados humanos más que en términos de relaciones entre distintos componentes y el mundo que las rodea (ver en este número el artículo de P. Kaulike que propone, a partir de Max Uhle, una reflexión sobre el trabajo interdisciplinario internacional).

Dividido por las fronteras de los modernos estados, el vasto territorio de los Andes del Centro-Sur no comparte hoy un mismo destino histórico. Cada uno de los países que lo compone: Argentina, Bolivia, Chile, Perú, promoviendo los valores nacionales, delinea su propia historia dentro de un marco territorial delimitado por fronteras recientes. A pesar de constituir, en muchos casos, dolorosas cicatrices que dan lugar a reclamos territoriales, estas cumplen el papel de garantes de la unidad territorial y de la historia por venir de cada uno de estos distintos Estados/naciones.

Sin embargo existen todavía grupos étnicos, sea porque acostumbran practicar el comercio o

* Directora de Investigación en CNRS, Paris. E-mail: therese.bouysse-cassagne@wanadoo.fr 
el contrabando, sea porque siguen poseyendo territorios que se encuentran más allá de los límites del espacio nacional actual, o porque vecinos de la frontera la consideran como una línea imaginaria, o porque son grupos nómadas ( $c f$. la reseña bibliográfica de X. Medinacelli sobre los pastores en este número) que cuestionan, por sus prácticas, los marcos rígidos de las líneas divisoras establecidas.

La política patrimonial de cada una de estas naciones funciona adentro de estos marcos y raras veces toma en cuenta un pasado, no tan remoto, que permitiría a varios Estados compartir los mismos valores culturales en un territorio mucho más extenso. Obviamente, y lo hemos comprobado recientemente a raíz de la elección del presidente Morales en Bolivia, se sigue apelando a los antiguos «lugares de memoria», en este caso Tiwanaku, para enraizar el presente en un pasado remoto y mítico. El valor legitimizante del pasado permite a cada nación fundar su presente. Lo que vale para Tiwanaku valió para Machu Pichu en Perú.

En algunos casos como el boliviano analizado en este volumen (ver artículo de Torres \& Romero), la política patrimonial — fundándose en recomendaciones de la UNESCO sobre la salvaguardia de la cultura tradicional y popular (1989) así como sobre la diversidad cultural (2001) — sirvió para generar nuevos referentes identitarios que surgieron a raíz de dinámicas sociales económicas y políticas recientes. Algunas entraron en conflicto con los intereses del Estado, otras no. En pocas palabras, el patrimonio se había convertido en un espacio de luchas en el que las tradiciones se redefinen o «se inventan» mientras que muchos de los referentes simbólicos, siempre más lentos en variar, perduran todavía - a veces por tan solo un breve lapso de tiempo-

Notaremos al respecto que las definiciones de la UNESCO a propósito del patrimonio inmaterial ${ }^{1}$, se apoyan en una concepción de la tradición que hace poco caso de la Historia, entendida esta según la definiciòn de Marc Bloch como «la ciencia de los Hombres en el Tiempo», es decir como ciencia de los cambios y del movimiento que obedece a una gran multiplicidad de estrategias. En efecto, la confrontación entre las sociedades «tradicionales» amerindias y el mundo contemporáneo - $-y$ esta advertencia vale también para el pasado- está concebida a menudo según un modo simplificador: o estas resisten o se apropian de los aspectos más eficientes de la gobalización para defender sus propias tradiciones, o se desmorronan en la anomia o desaparecen por aculturación.

Sabemos sin embargo que existen otras formas de pensar, y que podemos concebir las dinámicas culturales como una serie de «bricolage» en un espacio de recomposiciones múltiples, en función de los momentos, de las elecciones de los actores o de las numerosas presiones que estos aguantan.

El artículo de L. Rodríguez y M. Lorandi demuestra los múltiples usos del pasado como elemento básico del proceso de construcción de identidad, en dos momentos diferentes de la historia del Valle Calchaqui, analizando el rol que han tenido las escuelas, las instituciones políticas o el museo local, así como las disputas y la elaboración de identidades alternativas al discurso hegemónico.

Si nada puede evitar que cada generación reciba el pasado y lo cambie en funcción de las exigencias del presente, el trabajo histórico sobre el pasado puede favorecer sin embargo una apropiación crítica de las tradiciones (Ropaport, 1998).

No cabe duda que los fenómenos religiosos, con las diversas lógicas que promueven, desempeñan y desempeñaron un papel determinante en la comprensión de los problemas

1 Se entiende por patrimonio cultural inmaterial los «usos, representaciones, expresiones, conocimientos y técnicas - junto con los instrumentos, objetos, artefactos y espacios culturales que les son inherentes- que las communidades, los grupos y en algunos casos los individuos reconozcan como parte integrante de su patrimonio cultural. Este patrimonio cultural inmaterial, que se transmite de generación en generación, es recreado constantemente por las comunidades y grupos en función de su entorno, su interacción con la naturaleza y su historia, infundiéndoles un sentimiento de identidad y continuidad y contribuyendo así a promover el respeto de la diversidad cultural y la creatividad humana». (octubre de 2003) 


\section{Introducción}

políticos y sociológicos de los Andes del Centro-Sur. En efecto, los fenómenos religiosos ofrecen, tanto al arqueólogo como al historiador, un campo privilegiado para reflexionar sobre cómo las prácticas rituales y las formas simbólicas modelaron tanto los padrones de asentamientos como las formas de vivir. Sólo tomando en cuenta la diversidad de estas lógicas, y relacionándolas con la heterogeneidad de las estructuras sociales, tomando en cuenta sus cambios en las distintas épocas, se llega a una definición de la religión y de la sociedad que no sea esencialista.

Este número especial del Bulletin de I'IFEA analiza algunos de estos cambios y sus dinámicas en varios momentos de la historia de los Andes del Centro-Sur: en el Formativo Tiwanaku (artículo de L. Nuñez), Intermedio Tardio, época Inca en el territorio Pacaj (artículo de Kesseli \& Pärssinen), Intermedio Tardío y periodo Inca en la cordillera de Arica (I. Muñoz) en la pre-cordillera de Arica (J. Chacama), periodo Inca-periodo colonial en la región collagua (F. Duchesne) y en las minas del Collasuyo (T. Bouysse-Cassagne).

En 1928 Marc Bloch proponía como programa de investigación una historia comparada de las sociedades europeas. Definía su programa de la siguiente manera:

«Estudiar paralelamente sociedades a la vez vecinas y contemporáneas, influenciadas unas por otras o sometidas en su desarrollo en razón de su proximidad y de su sincronisación a la acción de las mismas causas, y teniendo, al menos parcialmente un origen común».

En su magistral estudio del templete de Tulan, L. Nuñez estudia el proceso formativo circumpuneño, desde una perspectiva regional comparatista al interior de particularidades propias del Centro-Sur andino.

Esta perspectiva comparatista no solo nos parece útil para una mejor definición de nuestro campo de análisis, sino para poner a prueba las explicaciones adelantadas, para inventoriar, diferenciar, encontrar analogías así como para comprobar la validez de los conceptos utilizados.

La colaboraciòn interdiciplinaria en cuanto esta utiliza las diferentes potencialidades de cada disciplina es igualmente eficaz, como demuestran Pärssinen, Kesseli y Duchesne en sus respectivos artículos sobre los chullpas de Caquiaviri para los dos primeros (Pärssinen, 1997) y las tumbas de Coporaque para este último, los resultados de la historia pueden utilizarse como hipótesis para el trabajo arqueológico. El método interdisciplinario, además de permitir periodizaciones correctas para la época precolonial, demuestra igualmente su fecundidad en cuanto se trata de entender la dinámica humana —comparando la distribución y los límites de varios fenómenos en una zona- así pueden surgir nuevos espacios étnicos precoloniales que ayudan a pensar las identidades de manera renovada.

Al situarse la historia en el interfaz de dos o varias tradiciones culturales tenemos como tarea la de precisar los tiempos de influencias culturales y sus modos de funcionamientos (Le Goff, 1967), de señalar las resistencias, de tomar en cuenta las mutaciones — que no hay que confundir con la nostalgia del pasado- y de lo que resiste al análisis — que no hay que confundir con el exotismo o el inmobilismo- (Ginzburg, 1980).

Privilegiar los procesos antes que las representaciones permite evaluar el margen de juego de los distintos actores cuando construyen o reconstruyen los códigos que rigen las relaciones sociales. Así los dos estados culturales separados por la Conquista no son disyuntivos y el estudio de todas aquellas formas sincretizadas o ambiguas que intentan dialectizar identidad y alteridad constituyen el punto extremo de una investigación pensada en términos comparatistas y relacionales (ver mi artículo en este mismo número). 


\section{Referencias citadas}

GINZBURG, C., 1980 - Préface. In: Le fromage et des vers, L'univers d'un meunier du XVle siècle; Paris: Aubier. Histoire.

LE GOFF, J., 1967 - Culture cléricale et traditions folkloriques dans la civilisation mérovingienne. Annales, E.S.C.: 780-791.

PÄRSSINEN, M., 1997 - Investigaciones arqueológicas con ayuda de fuentes históricas: experiencia en Cajamarca, Pacasa y Yampara. In: Saberes y memorias en los Andes. In Memoriam Thierry Saignes (Bouysse-Cassagne, ed.): 41-58; París-Lima: Credal-IFEA.

RAPPAPORT, J., 1998 - The politics of Memory, Native Historical interpretation in the Colombian Andes, 280 p.; Durham and London: Duke University.

UNESCO, 2003 - Anteproyecto de convención internacional para la salvaguardia del patrimonio cultural inmaterial. 